\title{
Perspectiva histórico-cultural e investigación antropológica en Chile: una aproximación a los aportes de Max Uhle, Martin Gusinde y Aureliano Oyarzún (1910-1947) \\ Historical-cultural perspective and anthropological investigation in Chile: an approach to the contributions of Max Uhle, Martín Gusinde and Aureliano Oyarzún (1910-1947)
}

\author{
Rodrigo Andrés Vásquez Vilches' (D) | Héctor Iván Mora Nawrath' (D) | Miguel Ignacio Fernández Lizanal (D) \\ Universidad Católica de Temuco. Temuco, Araucanía, Chile
}

\begin{abstract}
Resumen: Este artículo analiza la producción intelectual y contribuciones desde los postulados de la Escuela Histórico-Cultural austro-alemana en el desarrollo científico y fundamentación institucional de la antropología en Chile. Mediante una aproximación a la trayectoria y obra de Max Uhle, Martin Gusinde y Aureliano Oyarzún, se presentan algunos elementos que tienen por objetivo caracterizar los aportes en las investigaciones realizadas en el país, así como su contribución a las dinámicas socio-institucionales que permiten el nacimiento de la antropología científica hacia inicios del siglo XX. Para cumplir con dicho objetivo, se procedió mediante una aproximación de corte histórico, desde la cual se profundizó en el análisis de la producción científica de dichos autores. Esto permitió identificar y caracterizar actores, áreas de trabajo, núcleos temáticos comprendidos en el ejercicio antropológico, arqueológico y etnológico. Esta investigación entrega elementos que permiten discutir ciertas afirmaciones sobre la antropología a comienzos del siglo XX en Chile, entre ellas, la idea de la homogeneidad de sus prácticas, así como lo gravitante de su contribución con una política estatal de construcción de la nación.
\end{abstract}

Palabras-clave: Antropología en Chile. Método histórico-cultural. Ciencias antropológicas. Producción científica.

\begin{abstract}
This article analyses intellectual production and contributions from the perspective of the postulates of the AustroGerman Historical-Cultural School in the scientific development and the institutional establishment of anthropology in Chile. We use discussion of the careers and work of Max Uhle, Martín Gusinde and Aureliano Oyarzún to present a number of elements in order to characterise their contributions to the research work carried out in Chile, and to the socio-institutional dynamics which enabled scientific anthropology to emerge at the beginning of the 20th century. To attain this object we used a historical approach, from which we entered into more profound analysis of the scientific production of these authors. In this way we were able to identify and characterise actors, areas of work and core themes, including anthropological, archaeological and ethnological practice. The research produced various elements permitting discussion of certain statements made about anthropology in the early 20th century, among them the homogeneity of these practices, and their crucial contribution to a state policy of national construction.
\end{abstract}

Keywords: Anthropology in Chile. Historical-cultural method. Anthropological sciences. Scientific production.

VÁSQUEZ VILCHES, Rodrigo Andrés; MORA NAWRATH, Héctor Iván; FERNÁNDEZ LIZANA, Miguel Ignacio. Perspectiva históricocultural e investigación antropológica en Chile: una aproximación a los aportes de Max Uhle, Martin Gusinde y Aureliano Oyarzún (19101947). Boletim do Museu Paraense Emílio Goeldi. Ciências Humanas, Belém, v. 14, n. 2, p. 513-530, maio-ago. 2019. DOI: http:// dx.doi.org/10.1590/1981.81222019000200013.

Autor para correspondência: Rodrigo Andrés Vásquez Vilches. Manuel Montt, n. 56, Edifício A. Temuco, Araucanía, Chile. CEP $4780-000$ (rodrigvasquezv@gmail.com, hectmora@uct.cl).

Recebido em 26/10/2018

Aprovado em 21/02/2019
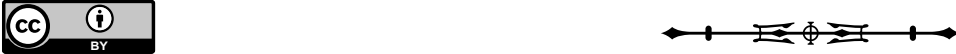


\section{INTRODUCCIÓN}

En Chile, la preocupación intelectual por las poblaciones indígenas que habitaban el país se inicia hacia fines del siglo XIX. Las distintas publicaciones que comienzan a aparecer bajo el formato de artículos, libros y notas resultan expresiones del interés por desarrollar diversas áreas de conocimiento (etnológico, físico, arqueológico, lingüístico, etnográfico), lo cual se grafica en el surgimiento de sociedades científicas -en sus respectivas revistas y secciones-, así como en la promoción y creación de instituciones abocadas al desarrollo de estas ciencias, como fueron los museos (Orellana, 1996, 1996; Pavez, 2015; Mora, 2016a, 2016b; Mora; Vásquez, 2018).

$\mathrm{Si}$ bien los esfuerzos llevados a cabo hacia fines del siglo XIX e inicios del $X X$ fueron importantes en el proceso de institucionalización de la antropología en Chile, fue en el periodo que abarcó entre 1910 y 1930 cuando se identifican las condiciones de posibilidad para un temprano desarrollo de la investigación científica y su proyección al espacio académico-formativo en los primeros cincuenta años del siglo XX (Orellana, 1996; Mora; Vásquez, 2018). Esto se demuestra tanto en el volumen y variedad de la producción y circulación intelectual, en la diversidad de sujetos-autores interesados en estas temáticas (etnológicas, arqueológicas, etnográficas, folclóricas, lingüísticas) (Tabla 1), como en la creación de espacios de sociabilidad y debate que se articulan en las sociedades científicas de la época (Figura 1). Es también la etapa en la cual emerge la única entidad dedicada al desarrollo de la antropología en Chile hasta la fundación del Instituto de Investigaciones Antropológicas de la Universidad de Chile (1954), el Museo de Etnología y Antropología (en adelante MEA) (Figura 3). A lo anterior podemos sumar el hecho de que en este periodo se comienzan a incluir algunos criterios de cientificidad asociados a la incorporación de teorías, métodos y evidencias (Cuadro 1), que se expresan tanto en la fundamentación de los textos producidos, como en los debates en torno a los temas y preguntas sobre el origen, relación y modos de vida de las poblaciones nativas del área sur de América (Orellana, 1996; Mora; Vásquez, 2018).

En este escenario, resulta de vital importancia la figura de Max Uhle (1875-1944)', indicado como aquel que desarrolló las bases de la arqueología científica en Chile, Martín Gusinde (1886-1969)2, quien desarrolló trabajo de

\footnotetext{
Formado en Filología en la Universität Leipzig (1875) y Königlich-Preussische Georg-Augustus Universität en Gotinga (1876-1877) (Dauelsberg, 1995). Se desempeñó como asistente en el Museo de Dresde (1881-1888) y en el Museo Etnográfico de Berlín. Desde 1892 realizó trabajos arqueológicos en Argentina, Bolivia y Perú con financiamiento de la Universidad de Pennsylvania, desarrollando un estudio estratigráfico en Ancón y Pachacamac para la fijación de una cronología relativa de la cultura Moche (Proto-Chimú) y Chincha-Ica (Nazca), además de conseguir financiamiento de la Universidad de California para realizar investigaciones en la costa y sierra norte peruana (Ramos, 2013). Fue fundador y director del Museo de Historia Nacional de Lima (1906-1911), posteriormente asumió la dirección del Museo de Etnología y Antropología de Chile (1911-1916) y fue director de la Sociedad de Historia y Geografía. Sus investigaciones se sitúan geográficamente entre los pueblos de la zona norte del país (Pisagua, Taltal y Arica) entre 1912 y 1919 (Dauelsberg, 1995; Santoro et al., 2010). Tras su paso por Chile, se radicó en Ecuador, donde se dedicó a desarrollar investigaciones en la zona costera de Esmeralda y Manabí, además de contribuir en la formación en Arqueología dictando clases en la Universidad Central en Quito (1919-1933). En 1933 regresó a Alemania para continuar con actividades académicas, dictando cátedras de Arqueología Andina en la Universidad de Berlín (Dauelsberg, 1995).

2 Comenzó sus estudios en el seminario de la misión en Heiligkreuz-Neisse. En 1905 realizó estudios superiores en Filosofía y Teología en San Gabriel. Hacia 1907 pasó a formar parte del noviciado de San Gabriel, donde fue ordenado sacerdote por la Orden del Verbo Divino. En 1911 fue enviado a Chile y residió en Santiago desde 1912, donde conjugó su labor como sacerdote en la iglesia de Zapallar y su trabajo como profesor de Ciencias Naturales en el Liceo Alemán (Feliú, 1969). Con respecto al cultivo de la antropología y etnología, comenzó a realizar investigaciones en la Araucanía (1916) y colaboró con otros intelectuales de la época, como P. Körting y Ricardo Latcham, en el estudio de los hallazgos de material arqueológico en Tierras Blancas. Su trabajo más reconocido tuvo lugar en Tierra del Fuego, entre 1918 y 1924. Tras su regreso a Alemania en 1924, se abocó a la redacción de su investigación doctoral y edición-publicación de su estadía en el extremo sur de Chile "Die Feuerland-Indianer" (1931-1939). Llevó a cabo investigaciones en Estados Unidos (pueblos indígenas de Arizona y Nuevo México; Conferencias en Universidad de Washington) (1928-1929; 1945); África (Pigmeos de Bambuti, Congo central, Rwanda) (1934-1935); Filipinas y Japón (1955, 1958); Colombia y Venezuela (Yupas, Guajiros) (1954); Nueva Guinea (1956); India (1958).
}

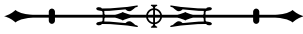


campo en el extremo sur del país en concordancia con las prescripciones de la etnografía moderna, y Aureliano Oyarzún (1858-1947)3 , articulador y promotor del desarrollo de la antropología y de los postulados de la Escuela Histórico-Cultural en Chile hasta su muerte en 1947.

La importancia de estos actores en el nacimiento de la antropología en el país, así como el impulso de ciertos marcos de análisis, es lo que motiva este artículo, que busca relevar el alcance que tuvieron estos actores, así como las propuestas teóricas que pusieron en escena en la conformación de la antropología en Chile a comienzos del siglo $X X$ (Cuadro 1). El foco de análisis se sitúa en los trabajos del arqueólogo alemán Max Uhle, del sacerdote alemán Martín Gusinde y del médico chileno Aureliano Oyarzún, en tanto se autodefinen y posicionan como representantes de la Escuela Histórico-Cultural en el espacio intelectual del país. En esta línea, el interés está puesto en exponer algunas de las propuestas y aportes realizados en los debates propios de la antropología de la época.

La metodología de la investigación consideró trabajo de archivo a partir del cual se sistematizaron diferentes fuentes escritas (cartas, artículos, libros e informes de administración), así como un conjunto de operaciones analíticas comprendidas dentro del análisis cualitativo de contenido (Andréu, 2000), aproximación que permitió visualizar los marcos cognitivos, actores, instituciones, núcleos temáticos y áreas de investigación asociadas a la obra de los integrantes de la Escuela Histórico-Cultural, que se manifiestan en el discurso científico de la época.

\section{ANTECEDENTES SOBRE LA ANTROPOLOGÍA EN ALEMANIA Y ESCUELA HISTÓRICO- CULTURAL}

La antropología científica surge a mediados del siglo XIX y es posible rastrear hasta las antropologías que emergieron en Alemania, Inglaterra, Francia y Estados Unidos (Azcona, 1984; Urry, 1984; Barth et al., 2012).

En el caso alemán, sigue la dinámica de formación de sociedades científicas, el surgimiento de políticas científicas y la definición de núcleos temáticos articuladores del quehacer en investigación, que tienen como base la distinción entre Völkskunde y Völkerkunde ${ }^{4}$.

En su origen, se destacaron las figuras de Rudolf Virchow (1821-1902) y Adolf Bastian (1826-1905)5, artífices de la fundación y dirección de museos y sociedades científicas, así como también de una serie de investigaciones. Dentro de las primeras instituciones que se tiene registro están los museos: Múnich (1868), Leipzig (1969), Etnológico de Berlín (1873), Viena (1876), Hamburgo (1878); las sociedades científicas: Berliner Gesellschaft für Antropologie,

\footnotetext{
3 Nacido en Chiloé, se trasladó para realizar estudios primarios en Puerto Montt y secundarios en Santiago. En 1879 finalizó sus estudios universitarios y se graduó de farmacéutico. Participó como parte del servicio sanitario y farmacología del Ejército durante la guerra del Pacífico. Continuó sus estudios en Medicina y en 1885 obtuvo el grado de médico cirujano. En 1887 se adjudicó una beca del gobierno para realizar estudios de Medicina en Francia y Alemania. A su regreso conformó la sección bacteriológica del Instituto de Higiene y fue designado como profesor de Anatomía Patológica y Patología General de la Universidad de Chile. Entre 1911 y 1912, visitó el Museo Etnológico de Berlín, lo que lo motivó a realizar trabajos de investigación en diversas regiones del país, considerando el estudio de material arqueológico (cestería, textiles, alfarería, tabletas) y etnológico (mitos y religión). Formó parte de diversas sociedades científicas y participó en variados congresos científicos. Fue director ad honorem del Museo de Etnología y Antropología de Chile y director del Museo Histórico Nacional.

4 La völkskunde remite a un modelo de ciencia nacional o "espíritu del pueblo" ligada al establishment de los estudios folklóricos (cuentos, proverbios, chistes, acertijos, consejos y leyendas inspirados en el conocimiento popular). Por otra parte, la völkerkunde es concebida como "ciencia de los pueblos del mundo", orientada por el interés de expansión geopolítica y cognitiva alemana que deriva en una agenda de investigación en América, África y Asia.

5 Ambos médicos de formación buscaron implementar un proyecto de institucionalización de la antropología en Alemania. Vinculado a un proyecto de construcción como nación, impregnado de las ideas políticas del partido liberal progresista, cuyo interés explícito era conformar una república científica (Bustamante, 2005). "La propuesta de Bastian es hacer de la etnología una ciencia integral de diversas disciplinas como antropología, fisiología, psicología, geografía, arqueología" (Pavez, 2015, p. 175), situándose en un modelo nomotético ligado a la corriente evolucionista que plantea la unidad psíquica de las culturas, siendo central la proposición de leyes para establecer que las predisposiciones mentales de los seres humanos son comunes en toda la humanidad.
}

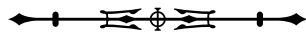


Ethnologie und Völkerkunde (1867); y las revistas: Zeitschrift für Ethnologie (1869) (Bunzl, 1996; Rebok, 2002; Gingrich, 2012; Mora, 2016a; Pavez, 2015).

Los orígenes de la denominada Escuela HistóricoCultural se remiten a la segunda mitad del siglo XIX, en los planteamientos del geógrafo y naturalista Carl Ritter (1779-1859), que posteriormente son retomados y perfeccionados por el geógrafo Friedrich Ratzel (18441904). Este último fundó su trabajo en el surgimiento de una nueva ciencia, a la que denominó "Antropogeografía", que se orientó hacia la "[...] localización de las regiones y la búsqueda de rutas de migración y difusión alrededor del mundo" (Barnard, 2004, p. 50, traducción nuestra). En términos teóricos, el aporte radica en la conceptualización de los "círculos culturales". Interesado por las olas migratorias y contactos entre culturas, buscó dar cuenta de la conexión histórico-geográfica a partir de la difusión de elementos culturales entre grupos humanos. El modelo de Ratzel asume como supuesto la idea de indeenarmut, es decir, el carácter poco inventivo de las culturas. Esto estriba en una condición a priori ligada a la idea de que los "[...] fenómenos culturales similares pueden ser resultado de fenómenos históricos distintos y extremadamente complejos" (Ulin, 1990, p. 22).

Estas ideas ganaron adeptos entre algunos intelectuales de la época, tales como: Bernhard Ankermann (1859-1943), Wilhelm Schmidt (1868-1954), Leo Frobenius (1873-1938), Willy Foy (1873-1929), Fritz Graebner (1877-1934), Wilhelm Koppers (1886-1961) y Paul Schebesta (1887-1967) (Gusinde, 1922; Harris, 1996; Barnard, 2004; Gingrich, 2012).

En este marco, es posible indicar que la institucionalización del método histórico-cultural no ocurre sino hasta la publicación de Die Methode der Etnologie (1911) del museólogo alemán Fritz Graebner. El propósito que persiguió dicho autor fue otorgar un método propio a la etnología dentro de un modelo de ciencia de corte historicista, es decir, buscar procedimientos que permitieran la reconstrucción de la historia de la cultura.
Para ello tomó como base la concepción de círculos culturales, definidos por la persistencia de rasgos que se esparcen en áreas geográficas debido a migraciones y relaciones de contacto y préstamo cultural entre diferentes grupos humanos, con el objetivo de establecer cronologías y levantar hipótesis sobre la transmisión cultural (Urry, 1984; Palerm, 2004).

Esta propuesta dio origen a algunas variantes, como fue la denominada rama austriaca de la Escuela Histórico-Cultural, que fue impulsada por Wilhelm Schmidt, sacerdote de la Orden del Verbo Divino que se dedicó a realizar trabajos de corte etnológico y lingüísticos acerca de las religiones primitivas. Intentó demostrar el origen de la humanidad a través del estudio de la organización social, del sistema económico y de prácticas y creencias religiosas. Su interés central fue fundamentar la existencia del monoteísmo religioso como elemento que se ha esparcido entre los círculos de los pueblos primitivos, rasgo caracterizador de su civilización. Junto a sus discípulos, los también sacerdotes Wilhelm Koppers y Martín Gusinde, conformaron la variante "verbista" de la corriente histórico-cultural en la Universidad de Viena y en el seminario de la misión en San Gabriel (Figura 2). Hacia 1906 fundaron el Instituto Anthropos y la revista del mismo nombre, instituciones que promovieron investigaciones y publicaciones científicas sobre las religiones "primitivas".

\section{LA PROPUESTA HISTÓRICO-CULTURAL EN CHILE}

El proceso de institucionalización de la antropología en Chile exhibe diferencias fundamentales, incluso en comparación con los devenires que adquiere dicho proceso en algunos países de América Latina (Mora, 2016a). Si bien hacia fines del siglo XIX aparecieron los primeros intentos por sentar sus bases, estos no lograron su consolidación como espacio autónomo que permitiera la diferenciación respecto a otras organizaciones científicas — la fase de diferenciación disciplinaria_; que en la mayoría 
de los casos alcanzó el estatus de sección en un museo, sociedad científica o revista. Tal vez lo más gravitante en su escasa proyección fue que no se produjera la apertura de cátedras universitarias y la creación de programas de formación profesional que permitieran el cultivo y proyección de la disciplina hasta mediados de la década de 1960 (Orellana, 1996; Mora, 2016a).

Esto nos lleva a afirmar que el proyecto de conformación de un campo de estudios antropológicos estuvo caracterizado por la fragilidad institucional, lo cual se expresa en la falta de continuidad en el tiempo y por la escasez de recursos económicos comprometidos para su desarrollo (Mora; Vásquez, 2018), que según la información recabada en los informes de administración, requerían: 1) implementación de una infraestructura adecuada a través del mejoramiento de los establecimientos, salas, estantes, etc.; 2) remuneraciones sostenidas y dignas para el personal investigador y de servicio - que apuntaba a la profesionalización-; 3) presupuestos dirigidos a la realización de la investigación —-trabajo de campo o expediciones -; 4) fondos necesarios para la difusión del conocimiento - publicación de revistas y boletines-.

Esta situación, asociada a las condiciones materiales de producción, permite entender la imposibilidad de que la propuesta histórico-cultural se constituyera como escuela en el país, a pesar del impulso inicial que recibió al alero del MEA (1916-1928), institución que albergó desde 1911 hasta su cierre en 1927 a Uhle (1911-1916), Gusinde (1913-1926) y Oyarzún (1912-1928) (Figura 3).

El desarrollo de esta perspectiva se remitió al intercambio entre Uhle, Gusinde y Oyarzún en su relación cotidiana en el MEA (Figura 3), como también a las formulaciones contenidas en los artículos que se publicaban en las diversas revistas científicas —entre ellas, la revista editada por el propio museo (Tabla 1) — o a las sesiones que tuvieron lugar en las sociedades científicas, en particular en la de Historia y Geografía, de la cual estos tres investigadores formaron parte y asumieron el rol de directores o jefes de sección.

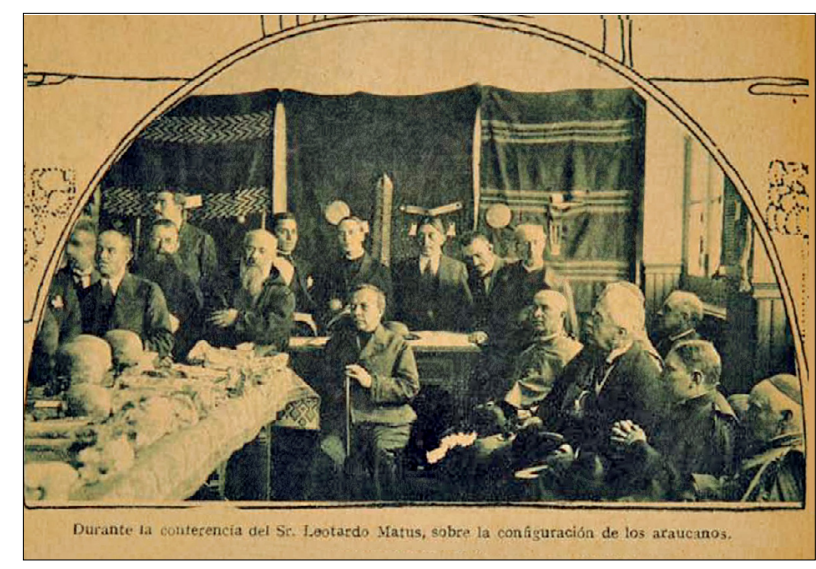

Figura 1. Congreso Araucanista Católico 1916. Sentado al centro y junto a las colecciones osteológicas, Leotardo Matus. De pie al centro detrás de Matus_-, Martín Gusinde, a su derecha Manuel Manquilefy F. Hieronymus von Amberg (Melchior Graf); a su izquierda el Cacique Catrileu y Aureliano Oyarzún. Sentado a la izquierda y en diagonal a Leotardo Matus, Max Uhle. Fuente: Mora y Vásquez (2018, p. 53).

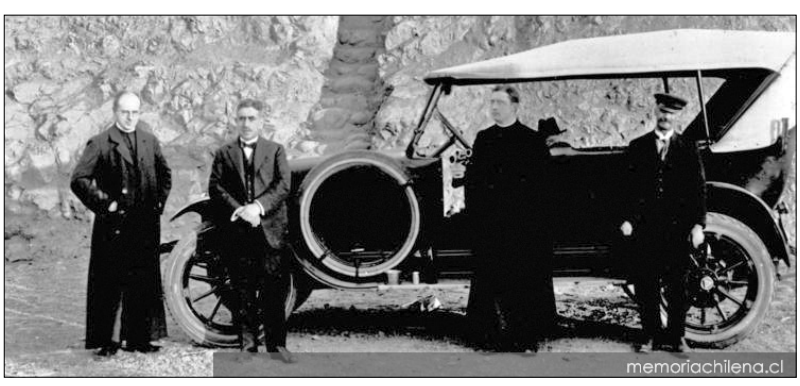

Figura 2. De izquierda a derecha: Wilhelm Koppers, Aureliano Oyarzún, Martín Gusinde y P. Vera. Wilhelm Koppers fue un sacerdote de la Congregación Verbo Divino y etnólogo alemán que realizó trabajo de campo en Tierra del Fuego entre 1921 y 1922. Fue director de la Revista Anthropos e impartió clases de Etnología en Viena. Fotografía tomada en la cumbre del Cerro San Cristóbal, Santiago de Chile, hacia 1920. Fuente: Memoria Chilena (2018).

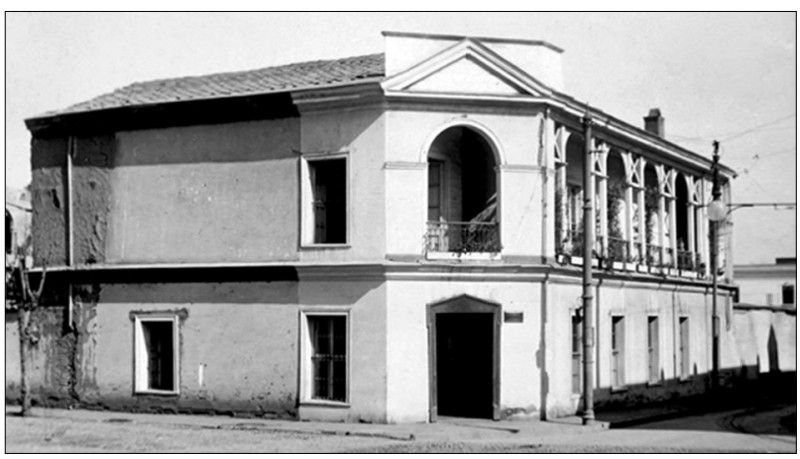

Figura 3. Museo de Etnología y Antropología hacia 1916. Fuente: Mora (2016a, p. 116).

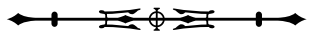




\section{EL MUSEO DE ETNOLOGÍA Y ANTROPOLOGÍA DE CHILE Y LAS PUBLICACIONES DEL MUSEO}

La creación del MEA responde al interés de la época de algunos intelectuales extranjeros y nacionales por impulsar el desarrollo de las ciencias del hombre a través de la apertura de sociedades científicas y museos, cuyo propósito fue brindar un panorama general de la situación actual y pasada de las poblaciones indígenas del país.

El MEA nació en el seno de la sección de Prehistoria del Museo Histórico 6 . Para su organización, fue contratado por el gobierno de Chile en 1911 el arqueólogo Dr. Max Uhle (Gusinde, 1916a), que tenía a su haber la fundación y dirección del Museo de Historia Nacional de Lima (19061911), así como una reconocida trayectoria en museos europeos, estudios de áreas culturales en Estados Unidos y en la región andina de América del Sur (Bolivia y Perú) 7 .

Max Uhle comenzó la organización del museo en 1912, a partir del material reunido por Rodulfo y Federico Philippi en el Museo Histórico Nacional, complementado con "[...] una riquísima colección de más de 3.800 objetos [...], 400 cráneos indígenas [...] y 50 momias [...]", fruto de la recopilación y las excavaciones que Uhle llevó a cabo en la zona norte desde su llegada al país (Gusinde, 1916a, p. 3). En esta dirección, el museo fue proyectado como una institución calificada para albergar y exhibir colecciones y financiar trabajos de investigación que desarrollaron tanto Max Uhle durante la primera etapa del museo, como Aureliano Oyarzún ${ }^{8}$ y Martin Gusinde posteriormente. La orientación general que guio el quehacer del museo fue la de transformarse en un centro de la cultura nacional y que permitiera "[...] ofrecer un campo de educación para el pueblo y otro de investigación para el sabio" (Gusinde, 1916a, p. 8).

Durante los primeros años de trabajo del museo, se recopiló una importante cantidad de material proveniente de las culturas del norte del país, que se complementó con el reunido por Oyarzún y Gusinde en la zona centro, sur y sur austral del país. A ello se sumó el aporte de índole privada (aficionado y estudioso) a través de donaciones con el objetivo de contribuir a salvaguardar el patrimonio cultural de la nación.

El museo abrió sus puertas al público en 1916, mismo año en que, por "[...] economías de la nación [...]", fue rescindido el contrato de quien fuera comisionado para su organización y dirección, el destacado arqueólogo alemán Max Uhle (Gusinde, 1916a, p. 4). La dirección ad honorem fue asumida por Aureliano Oyarzún a partir de 1916 y la plaza de jefe de sección fue ocupada por el sacerdote y etnólogo alemán Martín Gusinde (Figura 2).

Pese a los vaivenes económicos que experimentó el museo (Mora; Vásquez, 2018), bajo la dirección de Oyarzún se registró un hito relevante para la Escuela Histórico-Cultural: el inicio de las Publicaciones del Museo de Etnología y Antropología (1916-1927) (Tabla 1). Esta revista difundió trabajos originales en las áreas de arqueología-prehistoria, historia-etnohistoria, etnografía, etnología, folklore y lingüística realizados en el país, así como traducciones de referentes alemanes.

En 1926 Martín Gusinde fue cesado de sus funciones, misma suerte que corrió Carlos Reed, su reemplazo a partir

\footnotetext{
6 Los antecedentes del museo se remiten hasta las actividades de celebración de los 100 años de la independencia (1910), "[...] donde Aureliano Oyarzún Navarro fue encargado de [...] la retrospectiva histórica en la Exposición Histórica del Centenario, dedicando una de las 15 secciones de la exposición a la prehistoria de Chile" (Mora, 2016a, p. 115).

7 Existió interés de algunos gobiernos por la gestación y mantenimiento del MEA, pero resultó fluctuante a través de los años. Sin embargo, no logró consolidarse una política estatal consistente que permitiese el respaldo y promoción por parte del estado de las actividades propias del museo. En primer lugar, se recomendó al antropólogo y paleontólogo italiano Aldobrandino Mòchi, quien participó del congreso de Americanistas de Buenos Aires (1910). Sin embargo, luego de la muerte del presidente Pedro Montt, " [... . no logra concretar la contratación de Mòchi, y en su reemplazo, bajo el gobierno de Barros Luco, se contrata a Max Uhle [...]" (Mora, 2016a, p. 139-140) luego de su participación como expositor en los Congresos Científicos: Panamericano de Santiago (1908) y Americanista de Buenos Aires (1910).

8 Desde el año 1910 se inserta en la escena de investigadores que practicaron las ciencias humanas, con algunas publicaciones en el área de arqueología, dada su participación en calidad de comisionado por el Gobierno de Chile en el XVII Congreso de Americanistas de Buenos Aires (Orellana, 1979).
}

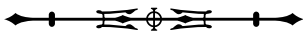


de 1924 (Oyarzún, 1927). Dicha determinación fue tomada durante el mandato de Carlos Ibáñez del Campo, cuya motivación obedeció a "[... . ] reducir gastos en el presupuesto de la nación [... ], formando parte de las medidas económicas y políticas que continuamente afectan sin mayor argumento los servicios culturales" (Feliú, 1970; Mora, 2016a, p. 118).

Bajo el argumento de reducción de gastos y a pesar de los aportes del museo en el marco de las investigaciones sobre la etnología, arqueología y antropología de las poblaciones indígenas del país, hacia el año 1928 por mandato gubernamental se decidió eliminar los recursos económicos a los Museos de Etnología y Antropología y de Historia, en función de una restructuración bajo una nueva institución denominada Museo Histórico Nacional (Latcham, 1929). Esto ha quedado fijado en los artículos 20 y 21 del $D$. F. L. n. 5.200 dictados el 18 de noviembre de 1929.

Artículo 20. El Museo Nacional de Historia Natural reunirá todos los materiales de Botánica, Zoología, Geología, Mineralogía, Paleontología, Antropología, Etnología y Arqueología universales. Incluirá en sus colecciones antropológicas, etnológicas y arqueológicas al hombre de Chile; pero la colección de base y preferencia relativa a la prehistoria chilena formará la sección de prehistoria del Museo Histórico Nacional.

Artículo 21. El Museo Histórico Nacional reunirá todos los objetos relacionados con la historia patria, tanto civil como militar, y con el ambiente y las costumbres de Chile en sus diversas épocas. En su sección de prehistoria, se limitará al aborigen chileno, con lo cual, en conformidad al artículo anterior, constituirá la colección de base y preferencia en el ramo, dentro del país. (Chile, 1922, p. 5).

Tras el cierre del MEA en 1929, Aureliano Oyarzún pasó al cargo de jefe de sección de prehistoria del Museo Histórico Nacional, para posteriormente en el mismo año ser nombrado director de dicha institución. Tras ser interrumpido en su cargo en 1931, retomó la dirección del Museo Histórico en el año 1936 hasta 1946, año en que dejó la dirección por problemas de salud (Orellana, 1979). Durante este periodo, Oyarzún continuó con la difusión de los presupuestos de dicha escuela en el país, mediante la participación en actividades como congresos y a través de publicaciones en revistas científicas (Figura 4).

Tabla 1. Cantidad de números y artículos incluidos en las Publicaciones del Museo de Etnología y Antropología (1916-1927). Fuente: Elaboración propia con base en los índices de las publicaciones.

\begin{tabular}{c|c|c|c}
\hline Año & Temas & Tomo/vol. & Cantidad de artículos \\
\hline 1916 & Arqueología y misceláneo & I (I) & 3 \\
\hline 1917 & Bibliografía, obituarios y etnología & I (2-3) & 6 \\
\hline 1917 & Arqueología, bibliografía, informaciones y etnología & $(4-5)$ & 5 \\
\hline 1920 & Etnología, memoria de gestión y etnohistoria & II (1) & 4 \\
\hline 1920 & Arqueología, bibliografía, etnología y misceláneo & II (2) & 7 \\
\hline 1920 & Arqueología, bibliografía, etnología, memoria de gestión, teoría y método & II (3) & 7 \\
\hline 1922 & Arqueología y etnología & III (1) & 2 \\
\hline 1922 & Etnología & III (2, 3-4) & 1 \\
\hline 1924 & Arqueología, etnología, etnografía y memoria de gestión & IV (1-2) & 6 \\
\hline 1927 & Arqueología, etnología, memoria de gestión, teoría y método & IV (3-4) & 10 \\
\hline
\end{tabular}

9 Gusinde había solicitado un permiso para ausentarse del país, con el objetivo de publicar su obra sobre los "fueguinos" y concluir sus estudios doctorales. Con respecto a Reed, Oyarzún agrega: "El reemplazante del señor Gusinde durante los tres años de ausencia en el extranjero, señor Carlos S. Reed, distinguido naturalista chileno, priva también al museo, por la misma disposición gubernativa, de su ilustrada y activa colaboración" (Oyarzún, 1927, p. 172).

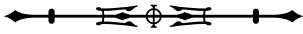




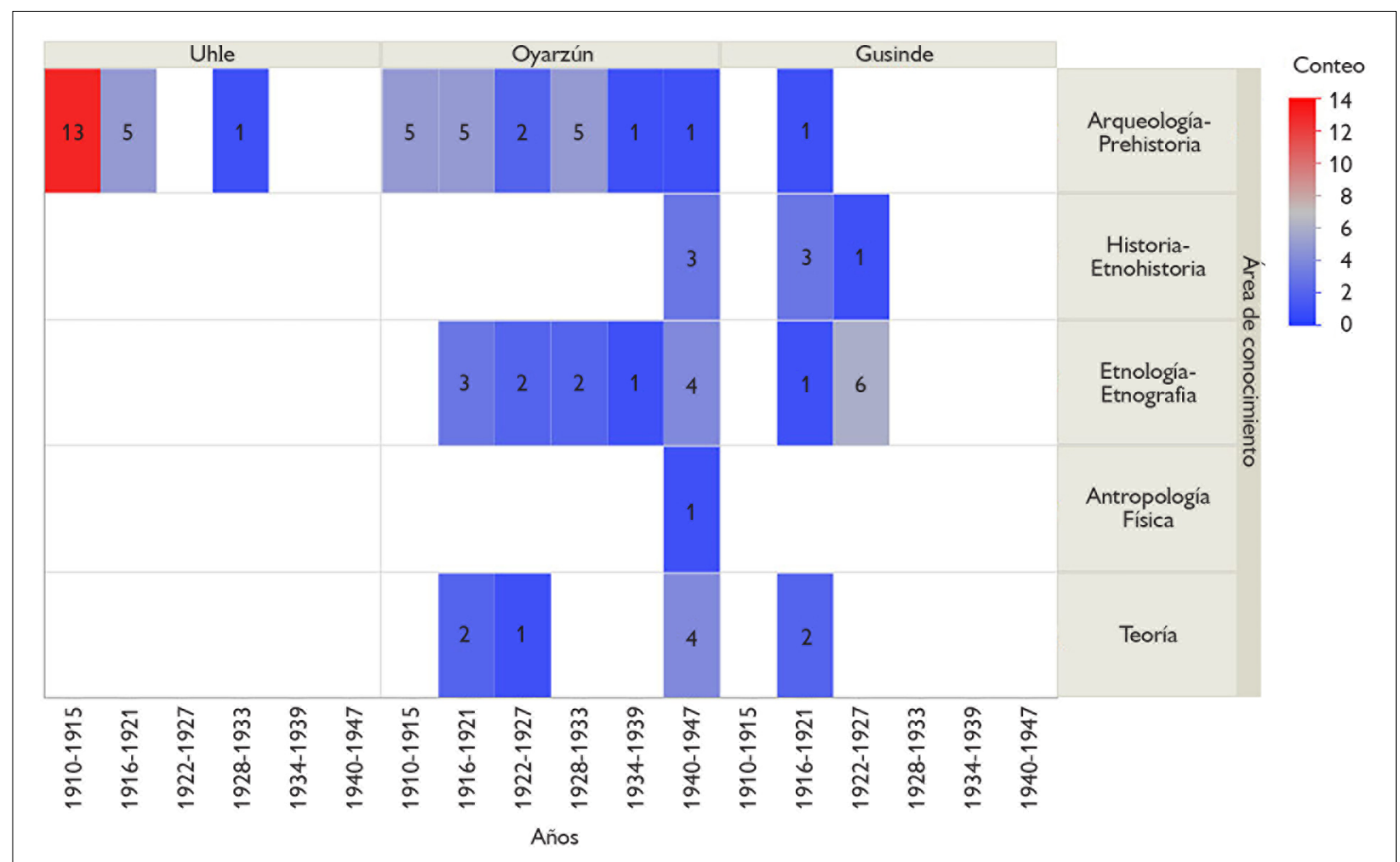

Figura 4. Producción científica de Uhle, Oyarzún y Gusinde según áreas de conocimiento, periodo 1910-1947. Fuente: Elaboración propia con base en las publicaciones de los autores.

\section{PRODUCCIÓN CIENTÍFICA, ÁREAS DE CONOCIMIENTO Y NÚCLEOS TEMÁTICOS}

Max Uhle fue uno de los primeros arqueólogos que llevó a cabo excavaciones en Chile utilizando las técnicas estratigráficas y el estudio de los contextos culturales, incorporando además el método comparativo a partir del cual buscó establecer vínculos entre las distintas etnias —empleó el uso de toponimias — tomando como eje el pasado prehispánico. Sin embargo, su trabajo se centró fundamentalmente en la creación de secuencias culturales y en la datación de las múltiples culturas y restos arqueológicos encontrados (Orellana, 1982). Según Erhardt (1998), Uhle realizó al menos cinco campañas en terreno, concentradas en las regiones desérticas del norte de Chile. En 1912 realizó excavaciones en el cementerio de Chunchurí (Calama), cuyos hallazgos atribuyó a la "Cultura Atacameña". En 1913 excavó tres cementerios indígenas en los alrededores del puerto de Pisagua. Estos trabajos le proporcionaron datos para elaborar una primera propuesta de secuencia base para la macrorregión del "Norte Grande". Posteriormente, en 1914 y 1915, llevó a cabo sondeos en aleros y basurales tempranos en los alrededores y en la ciudad de Constitución (al sur de Santiago). En 1916, luego de que el gobierno chileno cancelara su contrato, se asentó en el norte del país hasta su partida en 1919. Tras ser contactado por Augusto Capdeville, realizó trabajos arqueológicos en un conchal paleolítico de Taltal, donde a partir de

[...] la base de criterios netamente morfológicos,
caracterizó a los changos de Taltal como una
población remanente ligada a los 'Uros de la
altiplanicie y los atacameños' y los definió como
un 'grupo especial en oposición al tipo andino'
a 'juzgar por sus rasgos[...] más primitivos
evidentemente de orígenes más antiguos. (Santoro
et al., 2010, p. 354).

[...] la base de criterios netamente morfológicos, población remanente ligada a los 'Uros de la altiplanicie y los atacameños' y los definió como un 'grupo especial en oposición al tipo andino' evidentemente de orígenes más antiguos. (Santoro tal., 2010, p. 354)

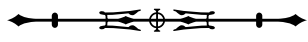


Aureliano Oyarzún mantuvo un itinerario de investigación bastante amplio, versado sobre áreas como arqueología, etnohistoria y etnología, con aproximaciones de corte descriptivo en la zona norte del país (Calama, Taltal, Melipilla, Casablanca, Quillota, Isla de Pascua y Llolleo), zona central (Malloa) y zona sur (Lautaro, Lonquimay y Chiloé). Se interesó por la aproximación multidisciplinaria (antropología física, etnología, etnohistoria, etc.), que se ve reflejada en variados trabajos publicados que retratan diversas regiones de Chile. Esto le permitió desarrollar una reflexión teórica sobre el método histórico-cultural aplicado al contexto chileno (Oyarzún, 1979). Cabe destacar que Oyarzún también publicó algunos trabajos sobre los fueguinos de Tierra del Fuego, sin embargo, estas son reproducciones del trabajo realizado por Gusinde o traducciones de trabajos publicados originalmente en alemán. Gusinde centró la mayoría de sus investigaciones en Chile en torno a los pueblos fueguinos del extremo sur (Selk 'nam, Alakaluf y Yámana), entre los años 1918 y 1923. Buscó conocer los atributos culturales en el estado primordial (organización social, parentesco, lengua, cultura material, mitología, religión, economía) y las dimensiones físico-patológicas de estos pueblos (cronometría, somatología y osteología). Al igual que un número considerable de trabajos realizados por los investigadores de la época, su investigación tuvo por objetivo el rescate de aquellos pueblos que entraban en vías de desaparición. Realizó una breve permanencia, de aproximadamente dos meses, en la actual región de la Araucanía, fruto de la cual publicó el trabajo "Medicina e higiene de los antiguos Araucanos" (1916) y "Otro mito del diluvio que cuentan los Araucanos" (1923). Para ello empleó un estudio de orientación histórica-etnohistórica (estudio y cotejo de fuentes documentales) y etnográfico (descripción de costumbres y conocimientos de los pueblos), en el que recurrió a fuentes orales y escritas. Asimismo, publicó un trabajo con base en los objetos contenidos en el MEA.

\section{APLICACIÓN DEL MÉTODO HISTÓRICO- CULTURAL EN LA OBRA DE UHLE, GUSINDE Y OYARZÚN}

La definición de un objeto de estudio —alteridad cultural radical - y la aplicación de un modelo teórico-metodológico son mecanismos de legitimación del trabajo científico y están relacionados con la obsesión por parte de los miembros de la Escuela Histórico-Cultural con la objetivación del dato (Silla, 2012) mediante los criterios de cantidad y forma. En este sentido, opera la crítica hacia el desconocimiento, prejuicios y falta de interés en profundizar sobre los diversos aspectos que constituyen la historia y cultura de los pueblos indígenas entre el circuito de estudiosos de la época y la opinión pública. Estos autores entran en disputas por la objetivación de sus observaciones como hechos verdaderos de la realidad y científicamente comprobables por el saber especializado.

Una segunda controversia tiene que ver con los debates sobre el encuadre metodológico de la antropología de la época. Inicialmente, se encuentran en estrecha conexión las descripciones de restos físicos, anatómicos y patológicos particularmente vinculados a las ciencias naturales. Para la corriente histórico-cultural, la concepción de antropología debía " [.... desprenderse como un campo autónomo de las ciencias de la naturaleza al considerar a la antropología como una ciencia humana vinculada a la historia" (Mora, 2016a, p. 148) (Cuadro 1). Dentro de esta lógica, en las publicaciones de Uhle, Gusinde y Oyarzún, se aplica un modelo que concibe como objeto de estudio a las poblaciones nativas que habitan el país desde una aproximación que pretendió establecer distancia con la tradición francesa fuertemente influenciada por las ideas suscitadas por Joseph De Gerando y Paul Broca en el marco de la Sociedad de Observadores del Hombre de París (Mora, 2016a).

Los autores sitúan las coordenadas del método histórico-cultural dentro de un modelo de ciencia de corte historicista que centra sus esfuerzos en la reconstrucción general de la historia de la cultura (Gusinde, 1922, 1951; Oyarzún, 1979) (Cuadro 1). Se pone de manifiesto la necesidad de generar descripciones sobre las formas 
Cuadro 1. Síntesis de las nociones sobre el método histórico-cultural presentes en la obra de Uhle, Gusinde y Oyarzún. Fuente: Elaboración propia con base en la literatura publicada por los autores.

\begin{tabular}{|c|c|c|}
\hline Max Uhle & Martin Gusinde & Aureliano Oyarzún \\
\hline $\begin{array}{l}\text { "Veo en mi imaginación toda } \\
\text { la secuencia histórica de las } \\
\text { culturas [...] tal como se } \\
\text { presentará ante los ojos de la } \\
\text { humanidad como resultado } \\
\text { de la investigación rigurosa, y } \\
\text { muchas veces dificultosa [...]. } \\
\text { Esto debería ser un resultado } \\
\text { de las investigaciones } \\
\text { conjuntas en los campos más } \\
\text { diversos" (Uhle, 1973, p. 12). }\end{array}$ & $\begin{array}{l}\text { "Aplicando el nuevo método (Kultur-historische Methode) } \\
\text { de la Etnología moderna a nuestras investigaciones comunes, } \\
\text { alcanzamos los resultados más halagüeños" } \\
\text { (Gusinde, 1916a, p. 6). } \\
\text { "[...] en la escuela moderna de la etnología, ya que pretende } \\
\text { ser una ciencia verdadera, no hay cabida para suposiciones y } \\
\text { presunciones, ni para hipótesis infundadas y arbitrarias; con un } \\
\text { método adecuado a su objeto material, procede a establecer } \\
\text { la realidad de los hechos, la verdad histórica, que por sí } \\
\text { permite formular conclusiones particulares y deducir principios } \\
\text { generales" (Gusinde, 1924, p. 42). }\end{array}$ & $\begin{array}{l}\text { "Sabemos, desde luego, que los } \\
\text { pueblos primitivos poseen muy distintos } \\
\text { grados de desarrollo cultural. Clasificar } \\
\text { estos grados, siguiendo el camino de } \\
\text { los más simples a los más compuestos, } \\
\text { ha sido la tarea del método cultural } \\
\text { histórico. [...] el método cultural } \\
\text { histórico [...] proporciona normas } \\
\text { seguras a la etnología de hoy que antes } \\
\text { descansaba en teorías psicológicas sin } \\
\text { fundamento objetivo real" } \\
\text { (Oyarzún, 1979, p. 3). }\end{array}$ \\
\hline
\end{tabular}

de vida y cultura material de las poblaciones indígenas, así como las particularidades ecológicas, ambientales y geográficas cuya finalidad es establecer cartografías de préstamos culturales (áreas culturales), sustentadas sobre la base de la articulación de información histórica, arqueológica y etnográfica (Cuadro 1).

Desde un punto de vista analítico, el esquema a aplicar está compuesto por los siguientes pasos: a) identificación de grupos aborígenes del país; b) establecimiento de los orígenes y procedencia de las culturas; c) identificación de posibles préstamos e influencias de culturas más avanzadas. La evidencia es susceptible de ser analizada en cráneos, en la cultura material en su extensión por un área geográfica e inclusive en la historia particular de cada pueblo.

\section{HIPÓTESIS LEVANTADAS POR LOS HISTÓRICO-CULTURALES}

Los autores sostienen la tesis de la influencia cultural entre los indígenas que habitaban Chile y las civilizaciones procedentes del Perú. Gusinde (1916b) señala que los estudios lingüísticos y arqueológicos dan cuenta de un largo y constante contacto entre ambos pueblos, desde los periodos que muestran la influencia de la cultura Tiahuanaco y Proto-Nazca.

El primer periodo de civilización peruana que señala Uhle (1911) ${ }^{10}$ es el de Ica y Nazca (400-600 d.C.). A pesar de no existir antecedentes concretos sobre el desarrollo de esta civilización, se conoce su paso entre los grupos pescadores salvajes a un estado de civilización. Generaron intercambios y relaciones con otros países, incorporando "[...] forma, pintura, dibujos y técnica de colores [...]" en el trabajo en alfarería (Uhle, 1911, p. 262).

El segundo periodo que reconoce es el de la civilización de Tiahuanaco y sus derivados (600-900 d.C.). Este periodo se caracterizó por el uso de conchas y adornos de ofrendas religiosas que han sido encontrados en Lima y en pozos de Huamachuco. Se desprende la influencia hacia regiones de las costas centroamericanas, en las faldas orientales de los Andes, los indígenas del este (Brasil) y en la cuenca norte de la altiplanicie ecuatoriana. Tiahuanaco habría sido la primera civilización en ejercer influencia hacia los pueblos que habitaban Chile a raíz del estudio de la ornamentación en una serie de vasos y alfarería.

\footnotetext{
10 En 1919 publicó "Arqueología de Arica y Tacna", donde presentó una secuencia cultural que se extiende a siete periodos: "Hombre primordial (hasta el fin de la era pasada); los aborígenes de Arica (primeros siglos d.C.); periodo contemporáneo con las ruinas de Chavin (400-600 d.C.); periodo de Tiahuanaco y subsiguiente epigonal (600-900 d.C.); periodo Atacameño indígena (900-1100 d-C.); periodo Chincha Atacameño (1100-1350 d.C.) y Periodo Inca (1350-1530 d-C.)" (Dauelsberg, 1995, p. 374).
} 
El tercer periodo caracterizado es el de los Incas (1450-1530). Abarcó entre cinco y seis generaciones, “[ ... ] desde el sur del Ecuador y hasta el norte de la Argentina y Chile, y por sus varios contactos con los indios del Este en el periodo anterior" (Uhle, 1911, p. 269). Algunos de los legados de las invasiones de los Incas a otros países fueron: la forma de gobierno, el sistema administrativo y militar, los caminos artificiales, el carácter lógico de la civilización, el ordenamiento político, la alfarería, las proporciones de sus artefactos (aurífero, barro, piedra).

Gusinde (1916b)y Oyarzún (1917) —quienes consideran a Uhle como su maestro- retoman estas cronologías en sus trabajos para fundamentar la tesis del contacto cultural entre indígenas chilenos y aquellos procedentes del Perú. Oyarzún (1979) señala que los estudios lingüísticos y arqueológicos han permitido dar cuenta de la influencia andina entre los araucanos, demostrada a través de la comparación de una serie de evidencias (alfarería, textiles, tabletas y pipas) en que los artefactos producidos por los "indígenas chilenos" no tendrían nada propio en su forma y contenido.

Una segunda hipótesis que se levanta por parte de los representantes de la perspectiva histórico-cultural es la de "revelar" la existencia del monoteísmo religioso entre los pueblos primitivos. Para estos efectos, el trabajo de Gusinde en Tierra del Fuego resulta de importancia en vista de proyectar la "influencia" de la Escuela Histórico-Cultural en el debate etnográfico nacional e internacional. En este sentido, la preocupación por dar cuenta de la dimensión religiosa en los pueblos primitivos es parte de una agenda de investigaciones lideradas por Wilhelm Schmidt y la Escuela de Viena con el propósito de superar las teorías evolucionistas de Edward B. Tylor, cuyos postulados sugieren "la emergencia del monoteísmo a través de un largo proceso de evolución religioso-cultural" (Pavez, 2012, p. 64).

\section{LA IMPORTANCIA DE LA HISTORIA Y LA GEOGRAFÍA}

Para los autores, resulta fundamental la valorización de la dimensión histórica en la aplicación del método.
Estos se orientaban a develar el conjunto de objetos pertenecientes a la cultura material de los pueblos, como también a dar cuenta del sistema de representaciones y prácticas difundidas e internalizadas en espíritu que anima la existencia de los pueblos. Podemos señalar que el énfasis del modelo se encuentra en esclarecer la historia antigua del continente americano respecto de aquellos pueblos cuyo pasado es desconocido para la ciencia moderna a causa de la falta de escritura (Uhle, 1918), al situarlas en un marco diacrónico y asignarle importancia a los aportes que provienen de la etnología, la arqueología, la prehistoria, el trabajo histórico-archivístico y la geografía como parte de la forma de proceder del método.

La aplicación del método se caracterizó por estadías de trabajo de campo relativamente breves (semanas o meses) durante periodos de receso de sus responsabilidades laborales entre los meses de diciembre y marzo. Esta dinámica les permitió compatibilizar la labor en el MEA con sus actividades laborales paralelas. Las excursiones se inscribieron dentro de un modelo clásico, en el que se buscó dar cuenta de la totalidad de fenómenos constituyentes de los grupos (idioma, cultura, derecho, religión, economía, organización social, parentesco, objetos de la cultura material, arte y técnicas) que orientaron la recopilación de datos etnográficos, etnológicos, arqueológicos, históricos, lingüísticos, visuales y físicos de las culturas.

En términos operativos, la dimensión espacial fue concebida bajo el concepto de áreas culturales para definir un esquema concreto y unitario de complejos de interacción entre pueblos que desarrollaron tecnologías, valores y prácticas comunes. A modo de ejemplo, Aureliano Oyarzún retomó el esquema de círculos culturales de Schmidt y sugirió un modelo que contiene una secuencia de siete áreas culturales que intentan describir el proceso de difusión geográfica de rasgos culturales entre los grupos americanos (recolectores, labradores y civilizaciones) a partir de definiciones con base en sistemas de alianzas de parentesco.

1. Área de cultura exo-monogámica

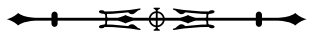


2. Área de cultura exogámica, totemista sexual

3. Área de cultura de iguales derechos

4. Área de cultura exogámica de derecho paterno

5. Área de cultura exogámica de derecho materno

6. Área de cultura de derecho materno libre

7. Área de cultura de derecho paterno libre

El autor sostiene como idea fuerza que la influencia peruana sobre los indígenas chilenos es anterior a la invasión Inca. La cultura denominada "atacama" estableció relaciones de influjos que permearon a los nativos en aspectos tales como la estilización, formas y dibujos en piedra y en alfarería, la agricultura y la cultura del derecho materno entre los araucanos. Los trabajos publicados en esta área por Aureliano Oyarzún resultan ser esfuerzos interpretativos centrados en confirmar la influencia peruana en los aborígenes chilenos, cuya supervivencia es susceptibles de ser encontrada hasta comienzos del siglo $X X$.

Empezaré por declarar que no he encontrado nada original en los productos de la cerámica chilena. $\mathrm{Ni}$ la forma de los vasos u objetos de greda ni sus dibujos, revelan una creación genuinamente nacional. En cada cosa que analizo descubro el sello peruano. (Oyarzún, 1979, p. 28).

En términos generales, los Histórico-Culturales asumen como supuesto apriorístico que la distribución geográfica de los objetos, toponimia y aspectos culturales (parentesco, organización social) provienen del norte (Perú), ya que estas culturas tienen un avanzado grado de desarrollo y pueden ser centros desde los cuales se esparcen hacia otras locaciones.

\section{LA ETNOGRAFÍA EN EL TRABAJO DE MARTIN GUSINDE}

Gusinde fue uno de los investigadores pioneros en realizar estudios con base en el trabajo de campo moderno. En efecto, la concepción de etnografía de la época hacía referencia a descripciones breves y en muchos casos sostenida sobre fuentes documentales, que involucran de manera muy parcial "[ ... ] la presencia u observación directa del 'investigador', y cuya finalidad era caracterizar y comparar las costumbres y tradiciones de las poblaciones" (Mora, 2016a, p. 167). El trabajo de Gusinde involucró su presencia como investigador, mediante estadías breves — de unos meses - entre los grupos estudiados, lo que le permitió generar descripciones-interpretaciones de la información recopilada de primera mano (entrevistas, fotografías, objetos de la cultura material y restos óseos), del contacto con informantes de campo y del análisis de los trabajos publicados y documentos de archivos sobre las poblaciones indígenas.

Gusinde realizó cuatro expediciones, en los meses de diciembre a marzo entre 1918 y 1924, a los grupos denominados fueguinos, con la pretensión de realizar una descripción detallada o totalizante de diversas dimensiones que comprenden el "espíritu" de los grupos fueguinos (creencias religiosas, vivienda, organización social, parentesco).

Las expediciones tenían diversos objetivos: a) incrementar las colecciones del MEA con objetos arqueológicos, etnográficos y antropológicos provenientes del extremo sur del país; b) fijar todos aquellos registros que acrediten la existencia de dichos pueblos, que se encontraban pronto a desaparecer, víctimas de los avances de la "civilización"; c) realizar un trabajo fuera del plano científico, que tenía que ver con la defensa y promoción de denuncias respecto a la vulneración de los derechos de la población fueguina (en este caso, del genocidio sistemático), la situación de abandono y recurrentes saqueos al patrimonio cultural del que fueron víctimas dichos grupos nativos.

\begin{abstract}
Se trataba de obtener, por lo tanto, antes de su total extinción, una descripción completa de las principales características raciales de los fueguinos, y habían de iniciarse inmediatamente las investigaciones. Esta urgente necesidad me hizo darme prisa, siendo la causa de muchas faltas en mis preparativos. No obstante, a última hora me fue posible, después de silencioso y penoso trabajo de investigación durante repetidas estancias en la Tierra del Fuego, acumular un inesperado y rico material científico y hacerme cargo del valioso tesoro espiritual de aquellos indígenas. (Gusinde, 1951, p. 129).
\end{abstract}

El texto etnográfico deja en evidencia el sentido de urgencia que significaba para los científicos la inminente 
desaparición de los pueblos indígenas y sus caracteres originales frente al progreso de la nación. Pese a no manifestar un posicionamiento crítico o compromiso hacia estas poblaciones, los autores relativizan las opiniones sesgadas que circulaban en los espacios de las elites intelectuales y políticas de la época, que se nutrieron, entre otras fuentes, de informaciones etnocéntricas sobre los grupos del extremo sur, por ejemplo, las que se encuentran contenidas en los diarios de viaje de Darwin (1945), ideas estigmatizadoras que se vieron difundidas y reproducidas por décadas en el imaginario de la sociedad nacional. Por otra parte, se levantan una serie de discusiones etnológicas de interés internacional, que pueden remitirse a las obras de autores como LehmannNitsche, Schmidt, Koppers, Boas y Rivet (Ballestero, 2011; Pavez, 2015), quienes profundizaron en distintos niveles las controversias que generaban los trabajos sobre los fueguinos.

Una segunda faceta que importa destacar de las incursiones entre los fueguinos es la relevancia que adquiere el registro fotográfico como documento de valor histórico y como parte de la aplicación del método. Al respecto, se releva el papel fundamental que juega la fotografía en el trabajo etnográfico de Gusinde" ${ }^{11}$, que es "[...] parte de un proceso de visualización del trabajo de campo y del encuentro intercultural, pero también en el espacio de análisis y difusión de la investigación en su calidad de autor" (Palma, 2013, p. 57). Ante la desconfianza de los fueguinos de enfrentarse a la cámara, y más aún, para "develar" la dimensión espiritual de su cultura, Gusinde puso en circulación la fotografía como parte de un "bien transable" dentro de una economía etnográfica, que le permitió generar lazos y establecer confianza con el objetivo de continuar realizando sus investigaciones en el ejercicio de la anthropologie — concepción alemana de antropología física—. Las fotografías constituyen referencias científicas sobre las dimensiones fenotípicas de las "razas fueguinas" en el marco del estudio fisiológico y somatológico para determinar las similitudes y diferencias entre los grupos fueguinos ${ }^{12}$. Estos elementos nos permiten pensar en la intención temprana de matizar y complejizar la práctica del trabajo de campo, respecto de la conjugación de los métodos adoptados, las técnicas y las herramientas de investigación operantes (Palma, 2013).

Finalmente, la preocupación etnográfica de los antropólogos del periodo por los pueblos indígenas se sitúa en un plano científico - legitimar su quehacer conforme al canon de la ciencia moderna- (Mora, 2016a, p. 195), mientras que posicionarse de manera ético-política frente a problemas sociales de las poblaciones resulta posterior al periodo analizado. Sin embargo, Gusinde introduce un aporte relevante para la época, que tiene relación con la denuncia frente a la situación de etnocidio y genocidio sistemático de las poblaciones indígenas en Tierra del Fuego mediante la exposición de comentarios generales en sus informes de expedición

\section{¿En dónde están los hombres fuertes, las mujeres de presencia gallarda y hermosa, la alegre juventud?...ंDónde están las mozas que buscaban mariscos en la playa, y los jóvenes que se adiestraban en el manejo del arco?....ंDónde están los cazadores y sus familias?...iPerecieron!....Están anonadados!... pero esta obra de desolación no la consumó ni la peste ni la guerra, sino el roce con los blancos y la codicia de los civilizados. (Gusinde, 2003, p. 39).}

Podemos advertir que el interés del autor se encuentra anclado en una dedicación moral de registrar para "salvar oportunamente" las tradiciones, costumbres, idioma, vale decir, perpetuar aquellos rasgos que desaparecen frente al "avance civilizatorio". En este sentido, la idea de

11 La utilización de la fotografía como herramienta estuvo ligada a pretensiones museográficas. Palma (2013, p. 79, 132) señala que detrás de la idea de la völkerkunde subyace el interés ligado a la creación de un "[...] museo fotográfico de las razas humanas [...]", idea de la que se impregna la obra de Gusinde, que le confiere un marco de autenticidad y legitimidad a su trabajo. En este sentido —y desde un punto "[...] cientificista — para los etnógrafos de la época, la fotografía permitía una clasificación objetiva de la diversidad cultural y racial humana" (Silva, 2014, p. 352, traducción nuestra).

12 La autora señala que, por lo general, el trabajo fotográfico de Gusinde busca retratar a los sujetos que representan de mejor manera los rasgos fenotípicos con relación al tipo ideal del grupo, tomando como referencia una matriz biológica que distingue entre lo "puro" y lo "impuro".

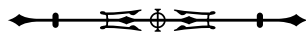


compromiso se encuentra ligada al interés por realizar un trabajo exhaustivo de dar a conocer y dejar un registro para las ciencias humanas que se proyecta hasta la actualidad.

\section{A MODO DE CIERRE}

En su reflexión en torno a las antropologías periféricas, Cardoso de Oliveira $(1996,1997)$ sostiene que lo particular de estas antropologías es su carácter estilístico respecto de lo que denomina matriz disciplinar. Destaca como rasgo constitutivo tanto la redundancia, como la prolongación de una idea, lo cual no implica necesariamente la incorporación de un aporte sustantivo a la capacidad explicativa, y añade que, a la luz del efecto del contexto y sus instancias empíricas, hace posible la complementación -como exceso de sentido - como un movimiento que permite dinamizar dicha matriz. En esta dirección, podríamos ampliar la idea de estilo a aquellas antropologías que se producen en los "países centrales" y pensar bajo esta óptica la propuesta teóricametodológica de la llamada Escuela Histórico-Cultural con relación a la singularidad que introduce respecto a otras propuestas antropológicas de inicios del siglo $X X$ y que tiene como objeto al "otro radical" (Peirano, 2008) (Cuadro 1).

Leída de este modo, la incorporación de los postulados histórico-culturales a la explicación del desarrollo y contacto entre las poblaciones pasadas y presentes en Chile puede ser pensada como la prolongación a nivel local de este estilo de antropología, que con base en sus condiciones institucionales y materiales "periféricas", no logra su reproducción y consolidación en el espacio científico y académico local.

Esta extensión estilística se entiende a través del establecimiento de una red de colaboración que se articula en torno al objetivo de impulsar y dar un carácter científico al estudio de las poblaciones indígenas en materia arqueológica, etnológica y etnográfica, objetivo que cobraba fuerza en la intelectualidad de varios países de América Latina. Max Uhle es visto como la figura científica que puede brindar dicho impulso, y aun cuando breve, su estadía en Chile permite introducir métodos y técnicas modernas, que se acoplan a ciertos objetivos trazados a nivel local: a) generar conocimiento científico sobre las "razas" o "etnias" que habitaban el país -en un encuadre con las problemáticas identificadas por la antropología de época_-, b) dejar testimonio o registro de las culturas que desaparecen o son absorbidas por el progreso, y c) desarrollar las ciencias antropológicas en tanto indicador de avance intelectual y progreso de una nación moderna (Porter, 1909; Latcham, 1909; Gusinde, 1916a).

En este contexto, la perspectiva histórico-cultural fue difundida en Chile por Max Uhle y Martín Gusinde y reproducida por Aureliano Oyarzún, quienes desplegaron esfuerzos colectivos e individuales para dar a conocer este método en el circuito de especialistas que cultivaron las ciencias antropológicas durante la primera mitad del siglo $X X$. Pese al interés de los autores por impulsar la actividad antropológica en el ámbito académico y universitario, esta adquirió poca relevancia para parte de las elites político-intelectuales de la época, lo que imposibilitó la consolidación de la perspectiva histórico-cultural como una escuela de pensamiento o un estilo de antropología institucionalizada, tal como ocurrió en el caso argentino ${ }^{13}$ Por otro lado, parece apropiado caracterizar el vínculo entre quienes conformaron la Escuela Histórico-Cultural en Chile bajo la noción de "colegios invisibles" (Crane, 1969), lo que implica la posibilidad de conformación de formación científica de comunidades interdisciplinarias, académicas o

\footnotetext{
13 La Escuela Histórico-Cultural se constituyó en una corriente de pensamiento hegemónica en la primera mitad del siglo XX (Valverde, 2015), que tuvo su nicho intelectual en la Sociedad Argentina de Antropología, en la Facultad de Ciencias Naturales y Museo de La Plata y la Universidad de Buenos Aires. Fue introducida en el país por el antropólogo italiano José Imbelloni (1885-1967) y difundida por Oswald Menghin (1883-1973), Salvador Canals Frau (1883-1958), Fernando Márquez Miranda (1807-1961), Enrique Palavecino (1900-1966) y Armando Vivante (1910-1996) (Guber, 2007; Ratier, 2010; Soprano, 2010), cuyos trabajos profundizaron en áreas como la arqueología, etnología, antropología, historia y prehistoria de los "pueblos primitivos" (Visacovsky et al., 1997; Ratier, 2010) y así se consagró la proyección de la escuela en el espacio académico universitario, ligada a la formación y profesionalización de la disciplina (Ratier, 2010) que se proyectó hasta finales de la década de 1960 (Guber, 2007).
}

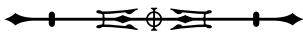


redes de cooperación formales e informales, la circulación de informaciones, discusiones de ideas y relaciones entre investigadores que permiten consolidar núcleos de intereses temáticos o tradiciones particulares que les son comunes ${ }^{14}$.

Aun cuando existió discontinuidad en la proyección de la perspectiva histórico-cultural en Chile, resulta necesario señalar una serie de aportes y esfuerzos que realizaron los autores en diversos niveles de su quehacer para el periodo analizado. Podemos destacar la importancia que adquirió Uhle como figura fundamental en la formación investigativa de la incipiente comunidad de estudiosos de esas nuevas ciencias en la lógica del maestro-aprendiz. El intercambio formativo, en la línea de los "colegios invisibles", tuvo como finalidad la enseñanza de una serie de procedimientos tendientes a la aplicación de teorías y métodos en el trabajo de campo, con el objeto de cumplir con los requisitos de cientificidad de la etnología moderna.

La importancia de la fijación de hipótesis y cronologías permitió dilucidar antecedentes sobre la prehistoria chilena, además de nutrir las discusiones a nivel nacional e internacional sobre los orígenes de las poblaciones indígenas del país. El aporte histórico-cultural radica en dar importancia a los contactos culturales de los indígenas que habitaron Chile con aquellos procedentes del Perú, bajo la hipótesis de la influencia de un área central hacia grupos receptores, que denota un largo periodo de contacto entre ambos pueblos, que se remonta hasta la cultura Tiahuanaco y Proto-Nazca. Gusinde y Oyarzún proyectaron el trabajo legado por Uhle en la zona norte en lo que podríamos denominar "división geográfica del trabajo antropológico", pasando por las investigaciones en la zona centro-sur de Oyarzún y extremo sur de Gusinde. El testimonio que los autores han dejado en sus documentos y publicaciones sobre la dedicación por consolidar el desarrollo de las ciencias permite imaginar el esmero por cultivar las ciencias antropológicas más allá de un mero pasatiempo.

La divulgación de la Escuela Histórico-Cultural en Chile concluye en 1947, tras la muerte de Aureliano Oyarzún. Las condiciones sociales, políticas e institucionales anteriormente expuestas imposibilitaron la conformación de una escuela que permitiera la transmisión formal de las ideas, que solo se hizo posible en Chile con la fundación de los programas académicos en arqueología y antropología que tuvo lugar durante la segunda mitad de la década de 1960, en la Universidad de Concepción (1966), Universidad de Chile (1970) y Escuelas Universitarias de la Frontera (actual Universidad Católica de Temuco) (1971).

\section{AGRADECIMIENTOS}

El artículo presenta algunos resultados de investigación en el marco del proyecto Fondecyt Iniciación 11170461 “Modelos de representación científica en el discurso especializado de orientación antropológica (1900-1945)", Conicyt, Chile.

\section{REFERENCIAS}

ANDRÉU, Jaime. Las técnicas de análisis de contenido: una revisión actualizada. Sevilla: Fundación Centro de Estudios Andaluces, 2000.

AZCONA, Jesús. La escuela histórica de Viena y la antropología vasca. Su alcance epistemológico en el contexto de la antropología europea. Cuadernos de Etnología y Etnografía de Navarra, Pamplona, año 16, n. 43, p. 137-152, anual 1984.

\footnotetext{
${ }^{14}$ A modo de ejemplo, Gusinde estableció comunicación con sus maestros en Viena para ser acompañado en sus expediciones a Tierra del Fuego e invitó a Wilhelm Schmidt a participar de la tercera expedición a Tierra del Fuego (1921-1922). Pese a que este último no pudo asistir, envió como comisionado a Wilhelm Koppers en su calidad de colaborador y editor de Anthropos. Es con Koppers con quien profundizó en los presupuestos del método histórico-cultural, que adoptó en sus trabajos etnológicos desde 1916, además de promover los recientes descubrimientos relativos a la creencia monoteísta entre los "fueguinos" en una serie de publicaciones, tales como los informes de expedición de Gusinde, el libro "Unter Feuerland-Indianern" de Koppers (1924) y la publicación de los volúmenes monográficos de la obra de Gusinde en Tierra del Fuego (1931-1974) y de las relecturas de los informes contenidos en las Publicaciones del MEA por Aureliano Oyarzún (1920-1945) (Tabla 1).

15 Hacia finales del siglo XIX y hasta mediados del siglo XX tuvieron lugar una serie de discusiones en torno al origen de las poblaciones indígenas que habitaron el país, donde se identifican los postulados de Barros Arana (1999) y Guevara (1899); Uhle (1916), Oyarzún (1979) y Gusinde (1916b); Medina (1882) y Latcham (1909) (Mora; Vásquez, 2018).
}

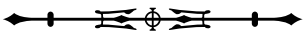


BALLESTERO, Diego A. "Los fueguinos”, Robert Lehmann-Nitsche y el estudio de los Onas en la Exposición Nacional de Buenos Aires (1898). História, Ciências, Saúde-Manguinhos, Rio de Janeiro, v. 18, n. 3, p. 789-810, jul./set. 2011. DOI: http://dx.doi.org/10.1590/ S0104-59702011000300011.

BARNARD, Alan. Diffusionist and culture-area theories. In: BARNARD, Alan. History and Theory in Anthropology. Cambridge: Cambridge University Press, 2004. p. 47-60.

BARROS ARANA, Diego. Historia General de Chile. Santiago de Chile: Editorial Universitaria, 1999. t. 1.

BARTH, Fredrik; PARKIN, Robert; SILVERMAN, Sydel; GINGRICH, Andre. Una disciplina, cuatro caminos: antropología británica, alemana, francesa, estadounidense. Buenos Aires: Prometeo, 2012.

BUNZL, Matti. Franz Boas and the Humboldtian tradition. In: STOCKING JR., George W. (ed.). Volksgeist as method and ethic: essays on Boasian Ethnography and the German Anthropological Tradition. Wisconsin: The University of Wisconsin Press, 1996. p. 17-78. (History of Anthropology, v. 8).

BUSTAMANTE, Jesús. La conformación de la antropología como disciplina científica, el Museo Nacional de México y los Congresos Internacionales Américanistas. Revista de Indias, Madrid, v. 65, n. 234, p. 303-318, cuatrim. 2005. DOI: https://doi.org/10.3989/ revindias.2005.i234.536.

CARDOSO DE OLIVEIRA, Roberto. Antropologías periféricas "versus" antropologías centrales. In: CONGRESO ARGENTINO DE ANTROPOLOGÍA SOCIAL, 5., 1997, La Plata. Anais [... . La Plata: Universidad Nacional de La Plata, 1997. Tema: Lo local y lo global: la Antropología ante un mundo en transición. p. 19-37.

CARDOSO DE OLIVEIRA, Roberto. La antropología latinoamericana y la "crisis" de los modelos explicativos: paradigmas y teorías. Maguaré, Bogotá, v. 11, n. 12, p. 9-23, sem. 1996.

CHILE. Decreto n. 5.200, de 18 de noviembre de 1929. Biblioteca del Congreso Nacional, Santiago de Chile, DTO-5200, DFL-5200, p. 1-39, enero 1992.

CRANE, Diana. Social structure in a group of scientists: a test of the "invisible college" hypothesis. American Sociological Review, New York, v. 34, n. 3, p. 335-352, June 1969. DOI: https://doi. org/10.2307/2092499.

DARWIN, Charles. Viajes de un naturalista alrededor del mundo Buenos Aires: El Ateneo, 1945.

DAUELSBERG, Percy. Dr. Max Uhle: su permanencia en Chile, de 1912 a 1919. Beiträge zurallgemeinen und vergleichenden Archäologie, München, v. 15, p. 371-394, 1995.

ERHARDT, Hannes. Max Uhle en Chile (1912-1919): sus aportes pioneros al estudio del precerámico costeño. Indiana, Berlin, v. 15, p. 107-138, sem. 1998.
FELIÚ, Guillermo. Martín Gusinde: la bibliografía de la Isla de Pascua y la de Antropología Chilena. Santiago de Chile: [s. n.], 1970. Disponível em: http://www.memoriachilena.cl/archivos2/pdfs/ MC0008159.pdf. Acesso em: 15 mar. 2019.

FELIÚ, Guillermo. El padre Martin Gusinde y su labor científica en Chile. Revista de Historia, Santiago, v. 1, n. 8, p. 19-41, 1969.

GINGRICH, Andre. Los países germanoparlantes. In: BARTH, Fredrik; PARKIN, Robert; SILVERMAN, Sydel; GINGRICH, Andre. Una disciplina, cuatro caminos: antropología británica, alemana, francesa, estadounidense. Buenos Aires: Prometeo, 2012. p. $85-144$.

GUBER, Rosana. Crisis de presencia, universidad y política en el nacimiento de la Antropología Social de Buenos Aires, Argentina. Revista Colombiana de Antropología, Bogotá, v. 43, p. 263-298, enero/dic. 2007.

GUEVARA, Tomás. Historia de la Civilización Araucana. Anales de la Universidad de Chile, Santiago, t. 102, p. 280-317, 1899.

GUSINDE, Martín. Primer Viaje a la Tierra del Fuego. Informe del Jefe de Sección. In: ORELLANA, Mario (comp.). La personalidad científica y humanística de Martín Gusinde. Santiago de Chile: Editorial Universitaria, 2003. p. 25-49.

GUSINDE, Martín. Hombres primitivos en la Tierra del Fuego: de investigador a compañero de tribu. Sevilla: Publicaciones de la Escuela de Estudios Hispano-Americanos, 1951.

GUSINDE, Martín. Cuarta expedición a Tierra del Fuego. Publicaciones del Museo de Etnología y Antropología de Chile, Santiago, t. 4, n. 1/2, p. 7-67, 1924.

GUSINDE, Martín. Métodos de investigación antropológica adoptados por el Museo de Etnología y Antropología de Santiago de Chile. Publicaciones del Museo de Etnología y Antropología de Chile, Santiago, t. 2, n. 3, p. 405-411, 1922.

GUSINDE, Martín. El Museo de Etnología y Antropología de Chile. Publicaciones del Museo de Etnología y Antropología de Chile, Santiago, t. 1, p. 30-47, 1916 a.

GUSINDE, Martín. Medicina e higiene de los antiguos araucanos. Trabajo presentado al Congreso Católico Araucanista de Santiago, en diciembre de 1916. Publicaciones del Museo de Etnología y Antropología de Chile, Santiago, año 1, n. 1, p. 87-121, 1916 b.

HARRIS, Marvin. El desarrollo de la teoría antropológica: historia de las Teorías de la Cultura. 12. ed. México: Siglo XXI, 1996.

KOPPERS, Wilhelm. Unter Feuerland-Indianern: eine forschungsreise zu den südlichsten bewohnern der erde mit $M$. Gusinde. Stuttgard: Verlegt von Strecker und Schröder, 1924.

LATCHAM, Ricardo. Memoria del Director del Museo Nacional. Boletín del Museo Nacional de Chile, Santiago, t. 12, p. 139-148, 1929.

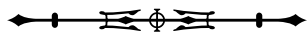


LATCHAM, Ricardo. Antropología Chilena. Revista del Museo de La Plata, La Plata, v. 16, p. 241-319, sem. 1909.

MEDINA, José Toribio. Los aboríjenes de Chile. Santiago de Chile: Imprenta Gutenberg, 1882.

MEMORIA CHILENA. Wilhelm Kopers, Aureliano Oyarzún, Martín Gusinde y P. Vera en la cumbre del cerro San Cristóbal, hacia 1920. Santiago: Biblioteca Nacional de Chile, 2018. Disponível em: http://www.memoriachilena.gob.cl/602/w3-article-74652.html. Acesso em: 15 mar. 2019.

MORA, Héctor; VÁSQUEZ, Rodrigo. La ciencia y lo "araucano" como ideas fuerza: Antropología y emergencia del "araucanismo" en Chile. In: MORA, Héctor; SAMANIEGO, Mario (ed.). El pueblo mapuche en la pluma de los araucanistas: seis estudios sobre construcción de la alteridad. Santiago de Chile: Ocho Libros, 2018. p. 22-87.

MORA, Héctor. La institucionalización de las Ciencias Antropológicas en Chile: una aproximación a las dinámicas socioorganizativas y cognoscitivas en la conformación del espacio científico (1860 y 1954). 2016. Tese (Doutorado em Ciências Sociais) - Facultad de Humanidades y Ciencias de la Educación, Universidad Nacional de La Plata, La Plata, 2016a.

MORA, Héctor. Dinámicas de campo en la emergencia de la antropología científica en Chile: algunas consideraciones y debates situados a inicios del siglo XX. CUHSO, Temuco, v. 26, n. 2, p. 107-145, 2016b. DOI: http://dx.doi.org/10.7770/CUHSO-V26N2ART1095.

ORELLANA, Mario. Historia de la arqueología en Chile (18421990). Santiago de Chile: Bravo y Allende Editores, 1996. (Colección de Ciencias Sociales).

ORELLANA, Mario. Investigación y teorías en la Arqueología de Chile. Santiago de Chile: Universidad de Chile: Centro de Estudios Humanísticos, 1982.

ORELLANA, Mario. Introducción. In: OYARZÚN, Aureliano. Estudios antropológicos y arqueológicos. Santiago de Chile: Editorial Universitaria, 1979. p. 10-24.

OYARZÚN, Aureliano. Estudios antropológicos y arqueológicos. Santiago de Chile: Editorial Universitaria, 1979.

OYARZÚN, Aureliano. Memoria del Museo de Etnología y Antropología. Publicaciones del Museo de Etnología y Antropología, Santiago, t. 4, n. 3/4, p. 169-172, 1927.

OYARZÚN, Aureliano. La sangre en las creencias y costumbres de los antiguos araucanos. Trabajo presentado al Congreso Católico Araucanista de Santiago, en diciembre de 1916. Publicaciones del Museo de Etnología y Antropología, Santiago, t. 1, p. 51-86, 1917.

PALERM, Ángel. Historia de la etnología: Tylor y los profesionales británicos. México: Editorial Universidad Iberoamericana, 2004. (Colección Teoría Social).
PALMA, Marisol. Fotografías de Martin Gusinde en Tierra del Fuego (1919-1924): la imagen material y receptiva. Santiago de Chile: Ediciones Universidad Alberto Hurtado, 2013.

PAVEZ, Jorge. Laboratorios etnográficos: los archivos de la antropología en Chile (1880-1980). Santiago de Chile: Ediciones Universidad Alberto Hurtado, 2015. (Colección Sociología, Personas, Organizaciones, Sociedad).

PAVEZ, Jorge. Disciplina científica colonial y coproducción etnográfica: las expediciones de Martin Gusinde entre los Yámana de Tierra del Fuego. Magallania, Punta Arenas, v. 40, n. 2, p. 61-87, 2012. DOI: http://dx.doi.org/10.4067/S0718-22442012000200004.

PEIRANO, Mariza. Antropología sin culpa, una visión desde Brasil. In: DEGREGORI, Carlos; SANDOVAL, Pablo (comp.). Saberes periféricos: ensayos sobre la antropología en América Latina. Lima: IFEA: IEP, 2008. p. 227-247.

PORTER, Carlos. Estado actual de las Ciencias Antropológicas en Chile. Revista Chilena de Historia Natural, Providencia, v. 13, n. 1, p. 110-122, trim. 1909

RAMOS, Alejandra. Max Uhle - Julio Tello: una polémica académicopolítica en la conformación de la Arqueología peruana. Runa, Buenos Aires, v. 34, n. 2, p. 197-214, dic. 2013.

RATIER, Hugo. La antropología social argentina: su desarrollo. Publicar en Antropología y Ciencias Sociales, Puán, v. 8, n. 9, p. 17-46, jun. 2010.

REBOK, Sandra. La constitución de la investigación antropológica alemana sobre América Latina a finales del siglo XIX. Revista de Indias, Madrid, v. 62, n. 224, p. 195-222, cuat. 2002. DOI: https:// doi.org/10.3989/revindias.2002.i224.464

SANTORO, Calogero; STANDEN, Vivien; ARRIAZA, Bernardo; ROTHHAMMER, Francisco. El legado de Max Uhle en la arqueología de Arica. In: KAULICKE, Peter; FISCHER, Manuela; MASSON, Peter; WOLFF, Gregor (ed.). Max Uhle (1856-1944): evaluaciones de sus investigaciones y obras. Lima: Fondo Editorial Pontificia Universidad Católica del Perú, 2010. p. 349-357.

SILLA, Rolando. Raza, raciología y racismo en la obra de Marcelo Bórmida. Revista del Museo de Antropología, Córdoba, v. 5, n. 1, p. 65-76, sem. 2012.

SILVA, James Roberto. Fotografia e ciência: a utopia da imagem objetiva e seus usos nas ciências e na medicina. Boletim do Museu Paraense Emílio Goeldi. Ciências Humanas, Belém, v. 9, n. 2, p. 343-360, maio/ago. 2014. DOI: http://dx.doi.org/10.1590/198181222014000200006.

SOPRANO, Germán. La enseñanza de la arqueología en la Facultad de Ciencias Naturales y Museo de la Universidad Nacional de La Plata. Un análisis sobre el liderazgo académico de Alberto Rex González y Eduardo Mario Cigliano (1958-1977). Revista del Museo de Antropología, Córdoba, v. 3, p. 171-186, 2010.

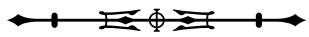


UHLE, Max. El método histórico en América. Indiana, Berlin, v. 1, p. 9-12, 1973.

UHLE, Max. Los aborígenes de Arica y el hombre americano. Revista Chilena de Historia y Geografía, Santiago de Chile, t. 27, n. 23, p. 33-54, 1918.

UHLE, Max. Sobre la estación paleolítica de Taltal, una carta y un informe. Publicaciones del Museo de Etnología y Antropología, Santiago, n. 1, p. 31-50, 1916.

UHLE, Max. La esfera de influencia del país de los Incas. In: TRABAJOS del cuarto congreso científico ( $1^{\circ} \mathrm{Pan}$-americano) celebrado en Santiago de Chile del 25 de diciembre de 1908 al 5 de enero de 1909. Santiago de Chile: Impr. Barcelona, 1911. p. 260-281.

ULIN, Robert. Antropología y teoría social. México: Siglo XXI, 1990.
URRY, James. A history of field methods. In: ELLEN, Roy (ed.). Ethnographic research: a guide to general conduct. Londres: Academic Press, 1984.

VALVERDE, Sebastián. El estigma de la difusión y la difusión del estigma: la escuela histórico-cultural y los prejuicios hacia los pueblos indígenas de Norpatagonia, Argentina. Relaciones de la Sociedad Argentina de Antropología, Buenos Aires, t. 40, n. 1, p. 327-349, enero/jun. 2015.

VISACOVSKY, Sergio; GUBER, Rosana; GUREVICH, Estela. Modernidad y tradición en el origen de la carrera de ciencias antropológicas de la Universidad de Buenos Aires. Redes, Buenos Aires, v. 4, n. 10, p. 213-257, sem. 1997. 